\title{
Correlation studies on incidence of eriophyid mite population A. guerreronis with weather parameters
}

K. BALAJI* AND Y. HARIPRASAD

Department of Entomology, Annamalai University, CHIDAMBARAM (T.N.) INDIA

\section{ARITCLE INFO}

Received : 21.01 .2016

Accepted : 17.03.2016

KEY WORDS :

Coconut, Eriophyid mite, A.guerreronis, Correlation

\begin{abstract}
A study was conducted at Department of Entomology, Annamalai University, Chidambaram, Tamil Nadu during 2000-2002. The meteorological parameters such as maximum, minimum temperatures, relative humidity, rainfall, wind velocity, hours of sunshine were correlated with mite population and correlation coefficients obtained were revealed that maximum, minimum temperature and wind velocity were positively correlated. Relative humidity, rainfall and sunshine were negatively correlated. The increase in these parameters decreased the mite population. By using the regression equations mean mite population $/ 8 \mathrm{~mm}^{2}$ can be predicted for a given set of meteorological parameters. A unit increase in maximum temperature keeping other parameters constant resulted in increase in population of $1.31 / 8 \mathrm{~mm}^{2}$ area. In contrast, a unit increase in rainfall resulted in decrease in mite population of $0.83 / 8 \mathrm{~mm}^{2}$.
\end{abstract}

How to view point the article : Balaji, K. and Hariprasad, Y. (2016). Correlation studies on incidence of eriophyid mite population A. guerreronis with weather parameters. Internat. J. Plant Protec., 9(1) : 268-271. 